\title{
Thermal Conversion of Municipal Biowaste Anaerobic Digestate to Valuable Char
}

\author{
Roberto Nisticò ${ }^{1, *} \mathbb{C}$, Federico Guerretta ${ }^{2}$, Paola Benzi ${ }^{2,3}$, Giuliana Magnacca ${ }^{2,4} \mathbb{C}$, \\ Davide Mainero ${ }^{5}$ and Enzo Montoneri ${ }^{6}$ \\ 1 Department of Applied Science and Technology DISAT, Polytechnic of Torino, C.so Duca degli Abruzzi 24, \\ 10129 Torino, Italy \\ 2 Dipartimento di Chimica, Università degli studi di Torino, Via P. Giuria 7, 10125 Torino, Italy; \\ federicoguerretta@gmail.com (F.G.); paola.benzi@unito.it (P.B.); giuliana.magnacca@unito.it (G.M.) \\ 3 CrisDi (Interdepartmental Centre for Crystallography), Via P. Giuria 7, 10125 Torino, Italy \\ 4 NIS Centre, Via P. Giuria 7, 10125 Torino, Italy \\ 5 ACEA Pinerolese Industriale S.p.A., Via Vigone 42, 10064 Pinerolo, Italy; \\ Davide.MAINERO@aceapinerolese.it \\ 6 Dipartimento di Scienze Agrarie, Università degli studi di Torino, Forestali e Alimentari, Largo P. Braccini 2, \\ 10095 Grugliasco, Italy; enzo.montoneri@gmail.com \\ * Correspondence: roberto.nistico0404@gmail.com; Tel.: (+39)0110904562; Fax: (+39)0110904624
}

Received: 5 January 2019; Accepted: 21 January 2019; Published: 23 January 2019

check for updates

\begin{abstract}
The municipal biowaste anaerobic digestate of a typical waste treatment plant is pyrolyzed under a mild condition (i.e., $540{ }^{\circ} \mathrm{C}$ ) to directly yield $\mathrm{N}$-doped biochar without performing any subsequent functionalization process. The results confirmed the integration of nitrogen heteroatoms within the carbonaceous framework. The morphological characterization, instead, evidenced the formation of a rather dense biochar with a very low surface area.
\end{abstract}

Keywords: biochar; biomass; carbon materials; pyrolysis; waste management

\section{Introduction}

The continuous need for alternative materials to replace fossil sources is rapidly emerging as a promising research field that will catalyze the technological development in the future [1-3]. Interestingly, in the last few decades, the use of carbon has remarkably grown and attracted attention worldwide thanks to the technological push that started with the discovery of its new allotropes (e.g., graphene, graphene oxide, and single- and multi-walled carbon nanotubes) as well as the positive integration of carbonaceous materials into breakthrough and challenging technological fields [4].

However, the production of carbon from natural sources following a simple thermal conversion of biomass from dedicated crops is a technological solution that no longer convinces scientists. It conflicts with food needs, raising concern about the exploitation of cultivation land for non-food purposes. This does not apply to the valorization of municipal biowaste (MBW) as a $C$ feedstock. Indeed, research in this direction is welcome to solve the environmental problems connected with the increasing amount of urban wastes [5,6].

In this context, water-soluble bio-based substances (SBO) have been obtained by the low-temperature alkaline hydrolysis of fermented MBW [2]. These substances have been shown to be efficient and active principles for the formulation and fabrication of products for use in chemistry, agriculture, and animal husbandry. These results offer the possibility to develop a biorefinery that, by integrating biochemical and chemical technology, produces a range of value-added products using MBW as a feedstock. To contribute to the realization of this scenario, the present work reports the pyrolysis of the SBO obtained from the MBW anaerobic digestate of a typical waste treatment plant. 
The authors of this work have already carried out previous studies [7-9] on the pyrolysis of several types of biowaste from both animal and vegetal sources. The pyrolysis of the MBW anaerobic digestate has not been reported yet. The present work shows that the pyrolysis of this material, performed under relatively mild conditions (below $700{ }^{\circ} \mathrm{C}$ ), yields biochar. It points out that, along with other chemical technologies $[2,10,11]$, pyrolysis may be complementary to convert an MBW treatment plant into a biorefinery that produces valued-added products.

\section{Materials and Methods}

\subsection{Reagents and Chemicals}

The MBW anaerobic digestate was sourced from the waste treatment plant of the ACEA Pinerolese Industriale S.p.A. (Pinerolo, Italy) by sampling from the biogas production plant line, which is fed with the organic humid fraction derived from the separate collection of urban refuse [11,12]. The MBW was hydrolyzed according to the previous work [10] to obtain the SBO. This material was washed repeatedly with hydrofluoric acid (HF, CAS 7664-39-3, 48\%, Merck, Kenilworth, NJ, USA) until the insoluble residue was ash free, then dried in an oven (Memmert, Schwabach, Germany) at $100{ }^{\circ} \mathrm{C}$ for one night and maintained in the dark in a closed vial until used. Hereafter, the HF-treated SBO is referred to with the MWDF acronym. The other reagents were: $\mathrm{NaOH}$ (CAS 1310-73-2, 98\%, Sigma-Aldrich, St. Louis, MO, USA), $\mathrm{HCl}$ (CAS 7647-01-0, 37\%, Fluka, St. Louis, MO, USA), and KCl (CAS 7447-40-7, 99\%, Fluka, St. Louis, MO, USA). All chemicals were used without further purification.

\subsection{Pyrolysis Process}

The pyrolysis of MWDF (ca. 2 g) was performed in a quartz tube reactor (LTF 12/38/500, Lenton, Hope Valley, UK) under an inert atmosphere (gas: $\mathrm{N}_{2}$, flux: $250 \mathrm{~mL} \mathrm{~min}^{-1}$ ) with the following thermal program: ramp from room temperature (RT) to the target temperature $\left(540{ }^{\circ} \mathrm{C}\right.$, rate: $\left.10^{\circ} \mathrm{C} \mathrm{min}^{-1}\right)$, followed by an isothermal step for $1 \mathrm{~h}$, and a non-controlled temperature decrease. The obtained MWDF char was washed twice with deionized water to remove all soluble residues, and then heated overnight at $80^{\circ} \mathrm{C}$ in an oven.

\subsection{Characterization Methods}

A TGA analysis was performed in a TGA Q600 (TA Instruments, New Castle, DE, USA), in nitrogen flux $\left(100 \mathrm{~mL} \mathrm{~min}^{-1}\right)$. Samples (ca. $10 \mathrm{mg}$ ) were heated from RT to $800{ }^{\circ} \mathrm{C}$ (heating ramp: $\left.10^{\circ} \mathrm{C} \min ^{-1}\right)$.

SEM measurements were performed by using a ZEISS EVO 50 XVP microscope (Zeiss, Zaventem, Belgium) equipped with an $\mathrm{LaB}_{6}$ source and a secondary electron detector, after sputtering a $15 \mathrm{~nm}$ Au layer onto the surface.

An elemental analysis of the precursor and the char was carried out in a Thermo FlashEA 1112 CHNS-O analyzer (Thermo Scientific, Waltham, MA, USA). The average values of three replicas are provided for each measurement.

FTIR spectra were recorded in transmission mode in a Vector 22 spectrometer (Bruker, Billerica, MA, USA) equipped with a Globar source and a DTGS detector and working with 128 scans at $4 \mathrm{~cm}^{-1}$ of resolution in the $4000-500 \mathrm{~cm}^{-1}$ range. The FTIR analysis was carried out on sample dispersed in KBr pellets (ratio 1:20).

XRD patterns were obtained on powders by means of a PW3040/60 X'Pert PRO MPD diffractometer (PANalytical, Malvern, UK) equipped with a $\mathrm{Cu}$ anode $(45 \mathrm{kV}, 40 \mathrm{~mA})$ and working in a Bragg-Brentano geometry.

The BET specific surface area (SSA) of MWDF char was quantified by performing a Kr adsorption isotherm at $77 \mathrm{~K}$ in an ASAP 2020 instrument (Micromeritics, Norcross, GA, USA). In order to remove the contaminants from the char surface, the sample was outgassed before analysis by heating at $150{ }^{\circ} \mathrm{C}$ for several hours under vacuum ( $\left.\mathrm{p}=10^{-2} \mathrm{mbar}\right)$. 
The $\zeta$ potential analysis was performed by dispersing a fixed amount of char (ca. $10 \mathrm{mg}$ ) in a $0.01 \mathrm{M} \mathrm{KCl}$ saline solution for 1 day and maintaining a constant temperature $\left(25^{\circ} \mathrm{C}\right)$ and $\mathrm{pH}(6)$. For the $\mathrm{pH}$ correction, $\mathrm{HCl}$ and / or $\mathrm{NaOH}$ aqueous solutions were added drop-wise. Measurements were carried out using electrophoretic light scattering (ELS) (Zetasizer Nano-ZS, Malvern Panalytical, Malvern, UK) using the Smoluchowski equation, an equilibration time before analysis of $120 \mathrm{~s}$, and five replicas for each specimen. The average values of two replicas were provided [13].

\section{Results and Discussion}

Figure 1 reports the thermal degradation profiles of MWDF performed under a nitrogen atmosphere. As shown in the figure, the thermo-gravimetric (TG) profile of MWDF presents two main weight losses. The first one is due to the loss of moisture at temperatures below $100{ }^{\circ} \mathrm{C}$ (ca. $5 \mathrm{wt} . \%$ ). The second thermal phenomenon started at the onset temperature of ca. $328^{\circ} \mathrm{C}$ and continued up to ca. $550{ }^{\circ} \mathrm{C}$. The analysis of the derivative TG plot (DTG) evidenced that such a degradation phenomenon seems to be bimodal, and probably this is due to an initial weight loss due to the carbohydrate residue of the MWDF, followed by the degradation of the humic-like fraction at higher temperature values (ca. $430^{\circ} \mathrm{C}$ ), in accordance with the literature [14,15]. A second lower-weight loss of residual organic matter occurs above $550{ }^{\circ} \mathrm{C}$. The results are consistent with previous TGA data for polysaccharides, such as chitosan [16] and humic-like substances isolated from composted biowaste [17]. Since a plateau of stability (in the range $500-600^{\circ} \mathrm{C}$ ) was registered soon after the main degradation phenomenon, the temperature selected for the pyrolysis treatment was $540{ }^{\circ} \mathrm{C}$.

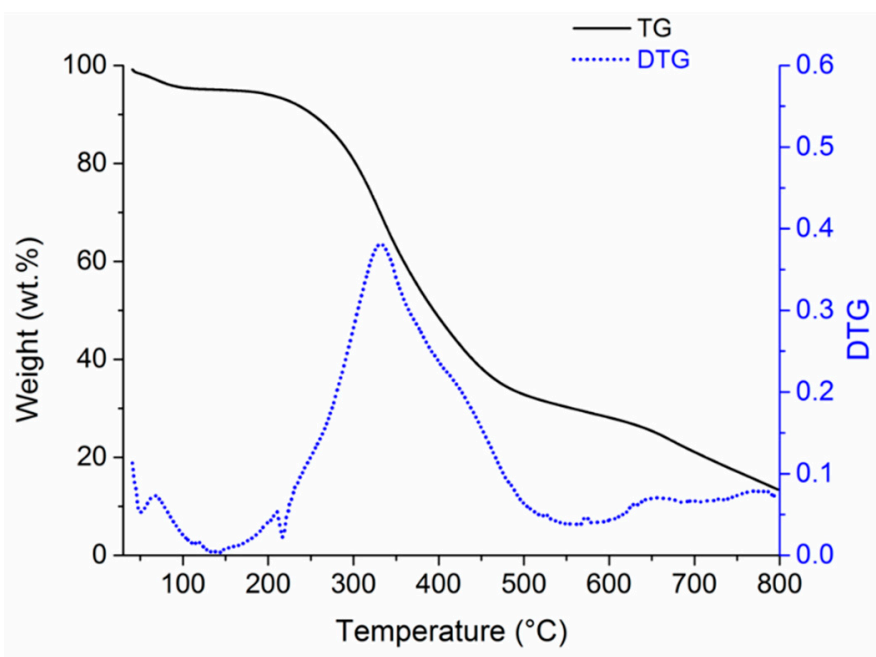

Figure 1. Thermo-gravimetric TG (black solid) and its derivative DTG (blue dotted) analyses of hydrofluoric-acid-treated, bio-based substances (MWDF) heated under a nitrogen atmosphere.

The chemical composition of MWDF and MWDF char were evaluated by an elemental analysis, and the data are summarized in Table 1 . As expected, with respect to the pristine MWDF, pyrolysis leads to a significant increase in the $\% \mathrm{C}$ (from $54.5 \%$ to $72.7 \%$ ) and a drastic reduction of the $\% \mathrm{H}$ (from $6.2 \%$ to $2.2 \%$ ), thus confirming the carbonization reaction. The heteroatom content $(\% \mathrm{~N})$, as already evidenced in our previous study [7], remains almost constant during the thermal process (from $7.5 \%$ to $7.2 \%$ ). This phenomenon could be attributed to a progressive inclusion of nitrogen species into cycloaliphatic and/or aromatic structures, forming a N-containing char. Additionally, the HF pretreatment of the precursor consists in a demineralization process, making the ash content in the MWDF almost negligible (below $1 \mathrm{wt} . \%$ ) [18]. 
Table 1. The elemental analysis, specific surface area (SSA), and $\zeta$ potential measurements.

\begin{tabular}{ccccccc}
\hline Samples & $\% \mathbf{C} \pm \mathbf{S D}$ & $\mathbf{\% H} \pm \mathbf{S D}$ & $\mathbf{\% N} \pm \mathbf{S D}$ & $\mathbf{C} / \mathbf{N}$ & $\mathbf{S S A}\left(\mathbf{m}^{\mathbf{2}} \mathbf{g}^{-\mathbf{1}}\right)$ & $\zeta$ Potential $(\mathbf{m V}) \pm \mathbf{S D}$ \\
\hline MWDF & $54.5 \pm 0.1$ & $6.2 \pm 0.1$ & $7.5 \pm 0.4$ & 7.3 & n.d. & n.d. \\
MWDF char & $72.7 \pm 4.7$ & $2.2 \pm 0.1$ & $7.2 \pm 0.3$ & 10.1 & 0.51 & $-45.6 \pm 1.8$ \\
\hline
\end{tabular}

To better evaluate the chemical modifications induced by pyrolysis, FTIR spectroscopy has been used to characterize the vibrational behaviors of the two samples (MWDF and MWDF char). As evidenced in Figure 2A, the MWDF spectrum presents characteristic signals at ca. $3400 \mathrm{~cm}^{-1}$ due to the $\mathrm{O}-\mathrm{H}$ and / or N-H stretching modes, a slight shoulder at ca. $3100-3000 \mathrm{~cm}^{-1}$ due to the aromatic $\mathrm{C}-\mathrm{H}$ stretching mode, and a more intense band at $3000-2800 \mathrm{~cm}^{-1}$ due to the aliphatic $\mathrm{C}-\mathrm{H}$ stretching mode, thus suggesting that the aliphatic organic fraction in MWDF is significantly higher than the aromatic one. Additionally, it is possible to observe the presence of bands in the $1700-1500 \mathrm{~cm}^{-1}$ range attributable to the presence of carbonyl functionalities, mostly amide $\left(\mathrm{ca} .1650 \mathrm{~cm}^{-1}\right.$ ) and carboxylate salts (ca. $1520 \mathrm{~cm}^{-1}$ ) [19]. The char produced by pyrolysis treatment at $540{ }^{\circ} \mathrm{C}$, instead, confirmed the carbonization process of MWDF, with the loss of the polar functionalities and the incipient formation of a broad signal in the $1600-1000 \mathrm{~cm}^{-1}$ range due to the presence of $C-C$ and $C=C$ groups [7].
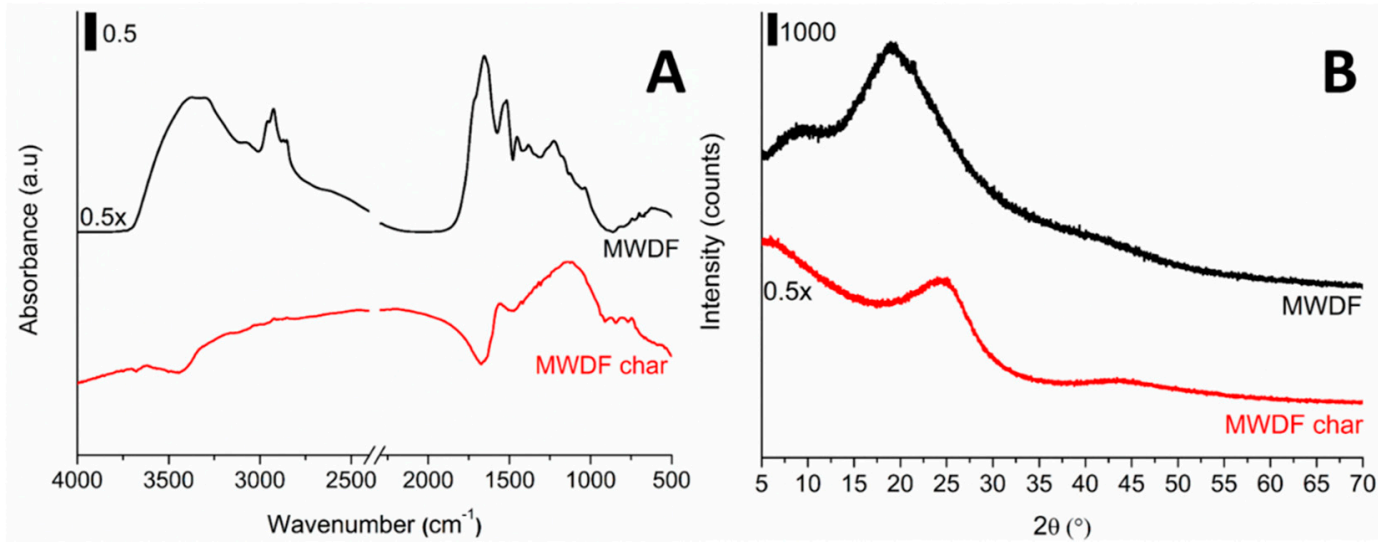

Figure 2. Panel (A) FTIR spectra in the $4000-500 \mathrm{~cm}^{-1}$ range of MWDF (black curve) and MWDF char (red curve); Panel (B) XRD patterns of MWDF (black curve) and MWDF char (red curve).

From the structural viewpoint, the XRD patterns of both MWDF and its char confirmed the absence of extended structural organization, showing only a broad signal centered in the ca. $2 \theta=23-25^{\circ}$ range with a slight shift toward ca. $2 \theta=26^{\circ}$ in the case of MWDF char, thus suggesting the formation of graphitic-like structures (Figure 2B).

The SEM micrograph for MWDF char (Figure 3) revealed a rather dense material with a certain degree of surface roughness. Such a dense structure was also confirmed by the very low value of SSA $\left(0.51 \mathrm{~m}^{2} \mathrm{~g}^{-1}\right)$, which was measured by using $\mathrm{Kr}$ as a probe molecule in order to evaluate with accuracy such a low specific surface area [20]. The surface charge of MWDF char was evaluated by performing a $\zeta$ potential measurement at constant $\mathrm{pH}$, temperature, and ionic strength, highlighting the formation of strongly negatively charged surfaces (see Table 1) useful for developing interactions with positive substrates. This behavior is in agreement with the literature for analogous systems [7,21]. 


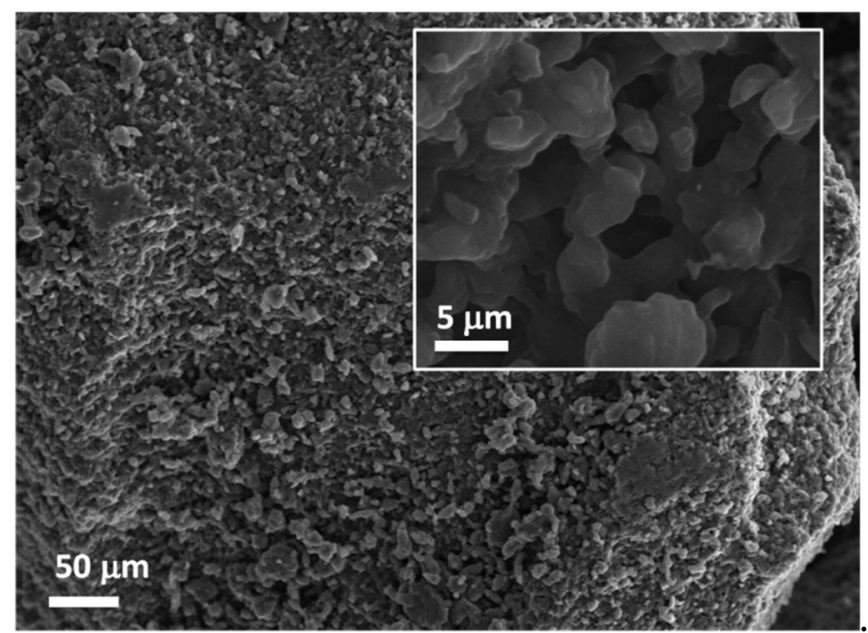

Figure 3. The SEM micrograph of MWDF char at low and high (inset) magnifications.

The research on the sustainable production of chemicals and/or carbon/char is a very promising research field that has continuously caught the attention of experts worldwide [22-27]. Among the possible processes, the direct $\mathrm{N}$-doping of carbon makes these materials very interesting for their exploitation as supercapacitors $[28,29]$ due to the enhanced conductivity, wettability, and electro-catalytic activity induced by the presence of heteroatoms within the carbon network [30]. In this context, the here-described research study proposes biowaste as an alternative precursor for the production of $\mathrm{N}$-doped carbons potentially exploitable in electrochemical applications. The present paper presents a case study showing how municipal biowastes can be valorized for the production of bio-based materials. Relevant benefits are expected for society from promoting research of this scope as the present case study aims to do. These benefits include offering worthwhile scope to the research community to promote further studies, developing technology and bio-based products from biowaste, and reducing biowaste landfilling, thus promoting a new biowaste-based industry.

\section{Conclusions}

In this study, the MWDF has been converted to biochar. The selected process was pyrolysis under mild thermal conditions (i.e., $540{ }^{\circ} \mathrm{C}$ ). The choice of maintaining mild conditions of biomass-to-char conversion has allowed us to retain the $\mathrm{N}$ content within the product's structure. This makes the above biochar attractive for future applications as a N-containing carbon material. The product's morphological and physicochemical characterization has revealed a rather dense carbonaceous material with very low specific surface area values. This result offers scope for further work that aims to increase the SSA by a proper catalyst or activation procedure. Within its limitations, the reported experimental work points out that is possible to convert MBW into valuable char and that pyrolysis is a valuable technology to consider when integrating other chemical and biochemical technologies for the valorization of biowaste as a source of value-added products.

Author Contributions: Conceptualization, R.N. and G.M.; Raw MBW, D.M.; SBOs Extraction, E.M.; Pyrolysis and Formal Analysis, F.G.; Elemental Analysis, P.B.; Writing-Original Draft, R.N.; Writing-Review, R.N., G.M., and E.M.; Funding, R.N.

Funding: This research was funded by the European Commission, project Mat4treaT (H2020-MSCA-RISE-2014, project number: 645551), and Polytechnic of Torino, project Starting Grant RTD (project number: 54_RSG17NIR01).

Acknowledgments: Additionally, the authors would like to acknowledge Domenica Scarano and Federico Cesano (University of Torino, Italy) for the use of the quartz tube reactor.

Conflicts of Interest: The authors declare no conflict of interest. The founding sponsors had no role in the design of the study; in the collection, analyses, or interpretation of data; in the writing of the manuscript, and in the decision to publish the results. 


\section{References}

1. Brodin, M.; Vallejos, M.; Opedal, M.T.; Area, M.C.; Chinga-Carrasco, G. Lignocellulosics as sustainable resources for production of bioplastics-A review. J. Clean. Prod. 2017, 162, 646-664. [CrossRef]

2. Franzoso, F.; Vaca-Garcia, C.; Rouilly, A.; Evon, P.; Montoneri, E.; Persico, P.; Mendichi, R.; Nisticò, R.; Francavilla, M. Extruded versus solvent cast blends of poly(vinyl alcohol-co-ethylene) and biopolymers isolated from municipal biowaste. J. Appl. Polym. Sci. 2016, 133, 43009. [CrossRef]

3. Woolf, D.; Amonette, J.E.; Street-Perrott, F.A.; Lehmann, J.; Joseph, S. Sustainable biochar to mitigate global climate change. Nat. Commun. 2010, 1, 56. [CrossRef]

4. Yang, Z.; Tian, J.; Yin, Z.; Cui, C.; Qian, W.; Wei, F. Carbon nanotube- and graphene-based nanomaterials and applications in high-voltage supercapacitor: A review. Carbon 2019, 141, 467-480. [CrossRef]

5. Esmaeilian, B.; Wang, B.; Lewis, K.; Duarte, F.; Ratti, C.; Behdad, S. The future of waste management in smart and sustainable cities: A review and concept paper. Waste Manag. 2018, 81, 177-195. [CrossRef] [PubMed]

6. Nisticò, R. Aquatic-derived biomaterials for a sustainable future: A European opportunity. Resources 2017, 6, 65. [CrossRef]

7. Anceschi, A.; Guerretta, F.; Magnacca, G.; Zanetti, M.; Benzi, P.; Trotta, F.; Caldera, F.; Nisticò, R. Sustainable $\mathrm{N}$-containing biochars obtained at low temperatures as sorbing materials for environmental application: Municipal biowaste-derived substances and nanosponges case studies. J. Anal. Appl. Pyrolysis 2018, 134, 606-613. [CrossRef]

8. Guerretta, F.; Magnacca, G.; Franzoso, F.; Ivanchenko, P.; Nisticò, R. Sodium alginate conversion into char via pyrolysis at the onset temperature. Mater. Lett. 2019, 234, 339-342. [CrossRef]

9. Magnacca, G.; Guerretta, F.; Vizintin, A.; Benzi, P.; Valsania, M.C.; Nisticò, R. Preparation, characterization and environmental/electrochemical energy storage testing of low-cost biochar from natural chitin obtained via pyrolysis at mild conditions. Appl. Surf. Sci. 2018, 427, 883-893. [CrossRef]

10. Baxter, M.D.; Acosta, E.; Montoneri, E.; Tabasso, S. Waste biomass-extracted surfactants for heavy oil removal. Ind. Eng. Chem. Res. 2014, 53, 3612-3621. [CrossRef]

11. Nisticò, R.; Evon, P.; Labonne, L.; Vaca-Medina, G.; Montoneri, E.; Francavilla, M.; Vaca-Garcia, C.; Magnacca, G.; Franzoso, F.; Negre, M. Extruded poly(ethylene-co-vinyl alcohol) composite films containing biopolymers isolated from municipal biowaste. ChemistrySelect 2016, 1, 2354-2365. [CrossRef]

12. ACEA Pinerolese. Available online: https://www.aceapinerolese.it/ (accessed on 8 November 2018).

13. Nisticò, R.; Celi, L.R.; Bianco Prevot, A.; Carlos, L.; Magnacca, G.; Zanzo, E.; Martin, M. Sustainable magnet-responsive nanomaterials for the removal of arsenic from contaminated water. J. Hazard. Mater. 2018, 342, 260-269. [CrossRef] [PubMed]

14. Miikki, V.; Hanninen, K.; Knuutinen, J.; Hyotylainen, J. Pyrolysis of humic acids from digested and composted sewage sludge. Chemosphere 1999, 38, 247-253. [CrossRef]

15. Palma, D.; Bianco Prevot, A.; Brigante, M.; Fabbri, D.; Magnacca, G.; Richard, C.; Mailhot, G.; Nisticò, R. New insights on the photodegradation of caffeine in the presence of bio-based substances-magnetic iron oxide hybrid nanomaterials. Materials 2018, 11, 1084. [CrossRef] [PubMed]

16. Corazzari, I.; Nisticò, R.; Turci, F.; Faga, M.G.; Franzoso, F.; Tabasso, S.; Magnacca, G. Advanced physico-chemical characterization of chitosan by means of TGA coupled on-line with FTIR and GCMS: Thermal degradation and water adsorption capacity. Polym. Degrad. Stab. 2015, 112, 1-9. [CrossRef]

17. Franzoso, F.; Nisticò, R.; Cesano, F.; Corazzari, I.; Turci, F.; Scarano, D.; Bianco Prevot, A.; Magnacca, G.; Carlos, L.; Martire, D.O. Biowaste-derived substances as a tool for obtaining magnet-sensitive materials for environmental applications in wastewater treatments. Chem. Eng. J. 2017, 310, 307-316. [CrossRef]

18. Ruppenthal, M.; Oelmann, Y.; Wilcke, W. Optimized demineralization technique for the measurement of stable isotope ratios of nonexchangeable H in soil organic matter. Environ. Sci. Technol. 2013, 47, 949-957. [CrossRef]

19. Rodríguez, F.J.; Schlenger, P.; García-Valverde, M. Monitoring changes in the structure and properties of humic substances following ozonation using UV-Vis, FTIR and ${ }^{1} \mathrm{H}$ NMR techniques. Sci. Total Environ. 2016, 541, 623-637. [CrossRef]

20. Beebe, R.A.; Beckwith, J.B.; Honig, J.M. The determination of small surface areas by krypton adsorption at low temperatures. J. Am. Chem. Soc. 1945, 67, 1554-1558. [CrossRef] 
21. Uchimiya, M.; Wartelle, L.H.; Klasson, K.T.; Fortier, C.A.; Lima, I.M. Influence of pyrolysis temperature on biochar property and function as a heavy metal sorbent in soil. J. Agric. Food Chem. 2011, 59, 2501-2510. [CrossRef]

22. Agblevor, F.A.; Jahromi, H. Aqueous phase synthesis of hydrocarbons from reactions of guaiacol and low molecular weight oxygenates. ChemCatChem 2018, 10, 5201-5214. [CrossRef]

23. Jin, Q.; Wang, X.; Li, S.; Mikulcic, H.; Basenic, T.; Deng, S.; Vujanovic, M.; Tan, H.; Kumfer, B.M. Synergistic effects during co-pyrolysis of biomass and plastic: Gas, tar, soot, char products and thermogravimetric study. J. Energy Inst. 2019, 92, 108-117. [CrossRef]

24. Jahromi, H.; Agblevor, F.A. Hydrodeoxygenation of aqueous-phase catalytic pyrolysis oil to liquid hydrocarbons using multifunctional nickel catalyst. Ind. Eng. Chem. Res. 2018, 57, 13257-13268. [CrossRef]

25. Munera-Echeverri, J.L.; Martinsen, V.; Strand, L.T.; Zivanovic, V.; Cornelissen, G.; Mulder, J. Cation exchange capacity of biochar: An urgent method modification. Sci. Total Environ. 2018, 642, 190-197. [CrossRef]

26. Ratajczak, P.; Suss, M.E.; Kaasik, F.; Beguin, F. Carbon electrodes for capacitive technologies. Energy Storage Mater. 2019, 16, 126-145. [CrossRef]

27. Antonelli, M.; Baccioli, A.; Francesconi, M.; Psaroudakis, P.; Martorano, L. Technologies for energy recovery from waste biomasses: A study about Tuscan potentialities. Energy Procedia 2015, 81, 450-460. [CrossRef]

28. Tong, X.; Chen, Z.; Zhuo, H.; Jing, S.; Liu, J.; Zhong, L. Tailoring the physicochemical properties of chitosan-derived $\mathrm{N}$-doped carbon by controlling hydrothermal carbonization time for high-performance supercapacitor application. Carbohydr. Polym. 2019, 207, 764-774. [CrossRef]

29. Ling, Z.; Wang, Z.; Zhang, M.; Yu, C.; Wang, G.; Dong, Y.; Liu, S.; Wang, Y.; Qiu, J. Sustainable synthesis and assembly of biomass-derived $\mathrm{B} / \mathrm{N}$ co-doped carbon nanosheets with ultrahigh aspect ratio for high-performance supercapacitors. Adv. Funct. Mater. 2016, 26, 111-119. [CrossRef]

30. Sridevi, G.; Narmatha, M.; Sathish, M. N-containing carbon/graphene nanocomposites for electrochemical supercapacitor applications. J. Nanosci. Nanotechnol. 2017, 17, 1267-1274. [CrossRef]

(C) 2019 by the authors. Licensee MDPI, Basel, Switzerland. This article is an open access article distributed under the terms and conditions of the Creative Commons Attribution (CC BY) license (http:// creativecommons.org/licenses/by/4.0/). 